\title{
Ocular rosacea - a review
}

\author{
Rosácea ocular - revisão
}

Ana Carolina Cabreira Vieira ${ }^{1}$, Ana luisa Höfling-Lima ${ }^{1}$, Mark J Mannis ${ }^{2}$

\begin{abstract}
Rosacea is a prevalent chronic cutaneous disorder with variable presentation and severity. Although considered a skin disease, rosacea may evolve the eyes in 58-72\% of the patients, causing eyelid and ocular surface inflammation. About one third of the patients develop potentially sight-threatening corneal involvement. Untreated rosacea may cause varying degrees of ocular morbidity. The importance of early diagnosis and adequate treatment cannot be overemphasized. There is not yet a diagnostic test for rosacea. The diagnosis of ocular rosacea relies on observation of clinical features, which can be challenging in up to $90 \%$ of patients in whom accompanying roseatic skin changes may be subtle or inexistent. In this review, we describe the pathophysiologic mechanisms proposed in the literature, clinical features, diagnosis and management of ocular rosacea, as well as discuss the need for a diagnostic test for the disease.
\end{abstract}

Keywords: Rosacea/diagnosis; Eye manifestations; Eye diseases; Rosacea/drug therapy; Doxycycline; Visual acuity

\section{RESUMO}

A rosácea é uma condição cutânea crônica, que possui apresentações clínicas variáveis. Apesar de considerada uma doença dermatológica, os ol hos podem ser acometidos em 58-72\% dos casos, causando inflamação palpebral e da superfície ocular. Aproximadamente um terço dos pacientes desenvolve acometimento corneano, podendo causar baixa visual significativa. Diagnóstico precoce e tratamento adequado são de extrema importância, devido à significativa morbidade ocular que a doença pode causar. Não há, até o momento, um teste diagnóstico para rosácea. O diagnóstico da rosácea ocular depende da observação das manifestações clínicas, o que pode ser bastante desafiador em até $90 \%$ dos pacientes, em que os achados cutâneos são discretos ou inexistentes. Nesta revisão, descrevemos os mecanismos fisiopatológicos propostos na literatura, manifestações clínicas, diagnóstico e tratamento da rosácea ocular, assim como abordamos a necessidade de um teste diagnóstico.

Descritores: Rosácea/diagnóstico; Manifestações oculares; Oftalmopatias; Rosácea/quimioterapia; Doxiciclina; Acuidade visual

\section{INTRODUCTION}

Rosacea is a widely prevalent chronic cutaneous disorder with variable presentation and severity. It primarily affects blood vessels and pilosebaceous units of the central facial skin (cheeks, chin, nose, and central forehead), causing transient or persistent erythema, telangiectasias, papules, pustules, and phymatous changes (Figure 1) $^{(1)}$.

Although considered a skin disease, rosacea may evolve the eyes in up to $58-72 \%$ of the patients, causing eyelid and ocular surface inflammation ${ }^{(1,2)}$. About one third of the patients develop corneal involvement, which may be sight-threatening ${ }^{(1,3)}$.

Rosacea, albeit common, is often overlooked by general practitioners and ophthalmologists ${ }^{(4)}$. Mild rosacea patients may not seek medical help and may not be diagnosed in clinical practice. Ocular rosacea, in particular, is frequently underdiagnosed. Its symptoms and signs can be quite non-specific, and in up to $90 \%$ of patients, accompanying roseatic skin changes may be very subtle. More importantly, in $20 \%$ of the cases, ocular signs may even precede characteristic skin involvement ${ }^{(3)}$. Patients often do not mention ocular symptoms in a dermatology clinic, unless directly asked about them. Conversely, skin manifestations are uncommonly examined during ophthalmology consults. As a result, a certain number of cases remain undetected ${ }^{(3)}$.

Chronic, untreated rosacea may cause varying degrees of ocular morbidity, facial disfigurement, emotional distress, and social impairment ${ }^{(5,6)}$. The importance of early diagnosis and adequate treatment cannot be overemphasized due to the negative impact this disorder may have on the quality of life of patients and the potential sight-threatening complications of this disease.

\section{EPIDEMIOLOGY}

Rosacea affects over 16 million Americans ${ }^{(7)}$, and a Swedish survey revealed a prevalence as high as $10 \%{ }^{(8)}$. A recent large observational study on the epidemiology of rosacea in the United Kingdom revealed an incidence rate of 1.65/1,000 person-years as diagnosed by general practitioners ${ }^{(9)}$. Women are more commonly diagnosed with rosacea than men, and they tend to be diagnosed earlier. A possible explanation for this is that women may seek medical care more often and earlier than men. On the other hand, men are more prone to phymatous changes ${ }^{(0,10)}$. Rhinophyma is most commonly seen in men over 40 years of age, in more advanced stages of the disease $e^{(11,12)}$.

Ocular rosacea affects both genders equally ${ }^{(9)}$. The incidence of ocular rosacea varies among ophthalmologic and dermatologic studies, ranging from 6-72\%, being more prevalent in ophthalmology clinics $^{(2,3,13)}$

Rosacea may be found in early childhood as well as in the elderly, but it most commonly affects middle-aged adults ${ }^{(14)}$. Spoendlin et al., found that $80 \%$ of rosacea patients in the UK were at or above 30 years of age, with a peak in the incidence rate between the ages of 40 and 59 years ${ }^{(9)}$. Pediatric rosacea is thought to be rare, but may be underreported since the dermatologic features are often absent or difficult to identify ${ }^{(15-17)}$.
Submitted for publication: August 7, 2012

Accepted for publication: August 23, 2012

Study carried out at Universidade Federal de São Paulo - UNIFESP - São Paulo (SP), Brazil.

Physician, Department of Ophthalmology, Universidade Federal de São Paulo - UNIFESP - São Paulo (SP), Brazil.

2 Physician, Department of Ophthalmology, University of California, Davis, CA, USA.
Funding: No specific financial support was available for this study.

Disclosure of potential conflicts of interest: A.C.C.Vieira, None; A.L.Höfling-Lima, employee of Federal Governement of Brazil; M.J.Mannis, None.

Correspondence address: Ana Carolina Cabreira Vieira, Rua Visconde de Silva, 52/503 - Rio de Janeiro - RJ - 22271-092 - Brazil - E-mail: anacarolinavieira31@gmail.com 


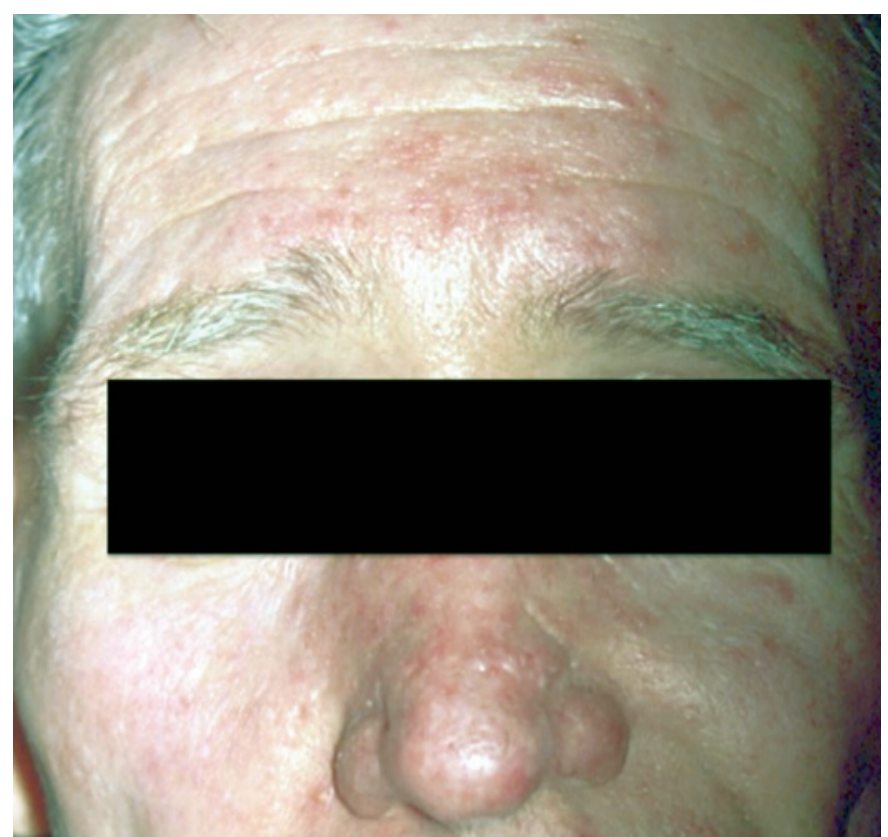

Figure 1.Cutaneous manifestations of rosacea with characteristic involvement of central facial skin (cheeks, nose, and central forehead).

Fair-skinned patients of European descent are more commonly affected by rosacea; however, any ethnicity can be afflicted with the disease. It has been suggested that skin pigmentation may obscure identification of the characteristic findings, contributing to underdiagnosis in dark skinned patients ${ }^{(18)}$.

\section{ETIOLOGY AND PATHOPHYSIOLOGY}

The precise etiology and pathophysiologic mechanisms of cutaneous and ocular rosacea remain unknown, although different theories have been proposed. Several studies confirm the inflammatory nature of the disease. An elevated concentration of interleukin-1 $\alpha$ and $\beta$ and a greater activity of gelatinase $B$ (metalloproteinase -9 ) and colagenase-2 (MMP-8) have been found in tear fluids of patients with ocular rosacea ${ }^{(19-22)}$. Doxycycline, used in the treatment of cutaneous and ocular rosacea, decreases both MMP-8 and MMP-9 activity ${ }^{(21,22)}$. Tumor necrosis factor (TNF-alfa) was also elevated in rosacea(23). Significant overexpression of ICAM-1 (intercellular adhesion molecule 1) and HLA-DR, inflammatory markers, was observed in conjunctival epithelial cells of patients with rosacea ${ }^{(24)}$.

Recently, studies have shown that disease exacerbation is stimulated by normal external environmental factors, leading to unique activation of pro-inflammatory systems as well as innate immune responses ${ }^{(23,25,26)}$. Molecular studies propose that the enhanced sensitivity of patients with rosacea may be caused by abnormal recognition of common environmental stimuli. Factors that trigger the innate immune system lead to an increase in the expression of certain cytokines and anti-microbial molecules in the skin ${ }^{(25,27)}$. Cathelicidin, one of these antimicrobial peptides, has both vasoactive and pro-inflammatory actions and is implicated in the pathogenesis of this disorder. Based on the observation of a single molecule that presents both vasoactive and pro-inflammatory actions, researchers decided to study the behavior of such molecule in rosacea. As hypothesized, these peptides were found in greater levels in the skin of individuals with rosacea than in normal facial skin(25,27,28). Moreover, the cathelicidin peptides found in rosacea patients were not only more abundant but were different from those found in normal individuals ${ }^{(25)}$. These forms of cathelicidin peptides are known for its role in natural host defense against infections and in promoting leukocyte chemotaxis, angiogenesis, and extracellular matrix component expression ${ }^{(27)}$. Supporting this theory, gene array studies found that mRNA expression levels of cathelicidin were found to be significantly increased in all subtypes of rosacea ${ }^{(29)}$. Additionally, local proteases (serine protease KLK5) that control the production of cathelicidin in epidermis were also abnormally expressed in rosacea patients ${ }^{(25,27)}$. To further test their hypothesis, researchers injected abnormal cathelicidin or protease that produce these peptides in the skin of mice and observed similar inflammatory features of the disease found in humans ${ }^{(27)}$. Observation of higher amounts of receptors of the recognition system, Toll-like receptor 2 (TLR2), in the epidermis of patients with rosacea explained the overreaction of these patients to environmental stimuli, since enhanced action of TLR2 in keratinocytes leads to an increase in serine protease KLK5 and cathelicidin production ${ }^{(23,25)}$. Interestingly, tetracyclines, which improve signs and symptoms of rosacea, are known to inhibit expression and activity of several matrix metalloproteinases ${ }^{(21)}$, as well as a class of proteases that activate cathelicidin, sustaining this theory ${ }^{(26,27)}$. Furthermore, a recent study found elevated concentrations of 5 molecules involved in the innate immune response (interleukin-1 $\beta$, interleukin-16, stem cell factor, monocyte chemotactic protein (MCP)-1, and monokine induced by $\gamma$-interferon) in cutaneous biopsy specimens taken from ocular rosacea patients, supporting the concept that ocular rosacea is a disorder of innate immunity ${ }^{(30)}$.

Vascular dilation and incompetence contribute to the signs and symptoms of rosacea. The characteristic facial flushing, persistent erythema and telangiectasia may be caused by altered cutaneous neurovascular homeostasis. Studies have demonstrated increased blood flow in the face and larger and more numerous vessels in the face than in other areas of the body ${ }^{(31)}$. Significantly dilated blood and lymphatic vessels were reported in all subtypes of rosacea ${ }^{(29)}$. Studies further demonstrated an up-regulation of genes involved in vasoregulation and neurogenic inflammation and suggested that dysregulation of mediators and receptors implicated in neurovascular and neuroimmune communication may be crucial at early stages of rosacea ${ }^{(26,29,32)}$. Improvement of erythema and flushing in rosacea by topical administration of $\alpha$-adrenergic receptor agonists, oxymetazoline and xylometazoline, helps support this theory ${ }^{(25,33,34)}$.

Cathelicidin causes endothelial changes ${ }^{(26)}$. Angiogenesis induced by cathelicidin is mediated by an increase in vascular endothelial growth factor (VEGF) in epidermal keratinocytes, and could represent an explanation for these vascular events in rosacea ${ }^{(25)}$. An increase in expression of VEGF and its receptors was demonstrated in the skin of patients with rosacea ${ }^{(35,36)}$.

Group IIA phospholipase $A_{2}$, an antimicrobial protein capable of killing Gram-positive bacteria, is secreted into the tears by lacrimal glands and plays a role in innate host defense. A decreased concentration of group IIA phospholipase $A_{2}$ was found in tears of patients with ocular rosacea ${ }^{(37)}$.

Microbial organisms such as Helicobacter pylori, Demodex folliculorum, Demodex brevis and Staphylococcus epidermidis have been appointed as other possible causative factors in exacerbation of the disease; however this remains a controversy ${ }^{(23,26,31,38-43)}$. The prevalence of H. pylori infection was found higher in patients with rosacea when compared to the general population, and its eradication has been shown to influence the clinical outcome of this disease ${ }^{(31,39,44-46)}$. However, other studies have not found such difference ${ }^{(41,47-49)}$. Demodex, a microscopic mite found in hair follicles and sebaceous glands, is the most common ectoparasite in humans. Studies support its role in the activation of immune mechanisms in certain subtypes of rosacea, especially papulopustular rosacea ${ }^{(32)}$. The Demodex count was shown significantly higher in patients with facial rosacea, and a study demonstrated a strong correlation between positive serum immunoreactivity and ocular Demodex infestation in facial rosacea and lid margin inflammation ${ }^{(41,50,51)}$. Another proposed mechanism 
is that Demodex mites may act as vectors for other microorganisms such as Bacillus olenorium, which may be responsible for initiation of inflammatory response in rosacea, through production of antigenic proteins and stimulation of Toll-like receptor 2 (TLR2) ${ }^{(23,25,38,42,50)}$.

\section{DIAGNOSIS}

The diagnosis of rosacea is clinical and relies on observation of skin manifestations. In cases in which these are only very subtle, the diagnosis can become very challenging and the disease may remain undiagnosed. In addition, manifestations of ocular rosacea are by no means specific to the disorder alone and other ophthalmologic diseases may present with similar findings, making the diagnosis even more difficult and the search for a diagnostic test quite important.

\section{LACK OF DIAGNOSTIC TEST}

Unfortunately, there is not yet a diagnostic test available for either cutaneous or ocular rosacea ${ }^{(15)}$. No serologic or histologic markers have been described to date. A diagnostic marker may enable earlier diagnosis and treatment, as well as contribute with an etiologic explanation for this troublesome disorder. Our group has been working on the glycomic profile of tears and saliva of roseatic patients, as an initial step in the long pathway towards the search for a biomarker for the disease. We have previously shown a high abundance of O-linked oligosaccharides in the tears of patients with rosacea ${ }^{(52)}$. More recently, we published our results on glycomic analysis of tears and saliva, and previous results were confirmed in both fluids with N-glycans dramatically decreased in roseatic tear and saliva samples ${ }^{(53)}$. Furthermore, we described highly novel glycans that may be potential biomarkers for rosacea ${ }^{(53)}$.

\section{Classification AND GRADING OF ROSACEA}

To aid in diagnosis, in 2002, an expert committee of the American National Rosacea Society published a standard classification system for rosacea ${ }^{(54)}$. As well as serving as a diagnostic tool, this classification facilitates communication among dermatologists, researchers and other specialists ${ }^{(54,55)}$. This important publication describes primary and secondary features of rosacea and defines 4 subtypes (erythematotelangiectatic, papulopustular, phymatous and ocular rosacea) and 1 variant (granulomatous rosacea) of the disease ${ }^{(54)}$. The primary

Table 1. Primary and secondary features of rosacea. Adapted from the Standard Classification of Rosacea, proposed by the National Rosacea Society Expert Committee, 2002 ${ }^{(54)}$

\begin{tabular}{ll}
\hline Primary features & Description \\
\hline $\begin{array}{l}\text { Flushing (transient erythema) } \\
\text { Nontransient erythema }\end{array}$ & $\begin{array}{l}\text { Frequent blushing or flushing } \\
\text { Papules and pustules }\end{array}$ \\
$\begin{array}{l}\text { Red papules with or without pustules. Nodules } \\
\text { may also occur } \\
\text { Telangiectasia } \\
\text { for a rosacea diagnosis }\end{array}$ \\
\hline Secondary features & Description \\
\hline $\begin{array}{l}\text { Burning or stinging sensations } \\
\text { Elevated plaques }\end{array}$ & \\
Dry appearance & Dry appearance of central facial skin \\
Edema & Facial edema \\
Ocular manifestations & \\
Peripheral location & \\
Phymatous changes & \\
\hline
\end{tabular}

and secondary features are listed in table 1. The presence of one or more of the primary signs with an axial facial distribution is indicative of rosacea. One or more of the secondary features may or may not be present.

Later, in 2004, the National Rosacea Society Expert Committee published a grading system to assess the severity of disease. Primary features were graded on a scale from 0 to 3 whether they were absent, mild, moderate, or severe, and most secondary features were graded as absent or present ${ }^{(56)}$.

\section{Diagnosis of OCULAR ROSACEA}

The diagnosis of ocular rosacea relies on observation of one or more of the following signs and symptoms: watery or bloodshot appearance (interpalpebral conjunctival hyperemia), foreign body sensation, burning or stinging, dryness, itching, light sensitivity, blurred vision, telangiectases of the conjunctiva and lid margin, lid and periocular erythema. Anterior blepharitis, meibomian gland dysfunction and irregularity of the eyelid margins may also be present ${ }^{(54)}$.

\section{Diagnosis of PEDIATRIC ROSACEA}

The clinical features of pediatric rosacea are similar to those observed in adults ${ }^{(16)}$. However, in children, the dermatologic findings are often absent, making the diagnosis even more challenging and the identification of ocular manifestations especially important ${ }^{(15,17,57)}$. A study revealed ocular symptoms to precede skin features in 55\% of children ${ }^{(58)}$. Ophthalmologists should maintain high suspicion in children with ocular surface disease, with or without cutaneous features, to avoid misdiagnosis and complications ${ }^{(59)}$. A positive family history of cutaneous rosacea and previous episodes of chalazia may be helpful in establishing the diagnosis ${ }^{(17)}$.

\section{CLINICAL FINDINGS}

\section{ROSACEA}

Symptoms may show periods of exacerbation and remission; however, the disease usually progresses over time. Some factors are known to worsen symptoms of rosacea and are referred to as trigger factors. Some examples of triggers are sun exposure, spicy foods, alcohol consumption, extreme temperatures, physical exercise, menopause and emotional distress such as anger and embarrassment. These factors tend to be specific to each individual. A recent large epidemiologic study revealed that alcohol consumption is associated with only a small increase in risk of developing rosacea, whereas smoking may actually substantially reduce such risk ${ }^{(9)}$.

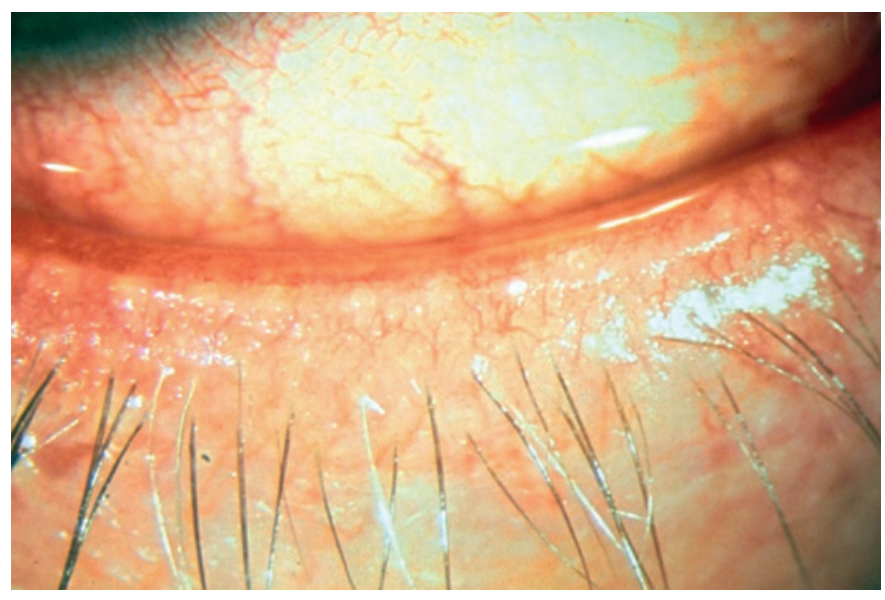

Figure 2. Eyelid margin of a patient with ocular rosacea showing meibomian gland dysfunction and telangiectases. 


\section{Ocular rosacea}

Patients with ocular rosacea may complain of foreign body sensation, dryness, itching, photophobia and tearing ${ }^{(10,60)}$. Decreased visual acuity may result when corneal involvement is present.

Ocular manifestations are usually bilateral and, as previously mentioned, can be non-specific ${ }^{(15)}$. The severity of ocular rosacea symptoms is often not related to the severity of cutaneous manifestations $s^{(15,31,51,60,61)}$. One study found a significant relationship between ocular involvement and the severity of telangiectasia ${ }^{(62)}$

\section{Eyelids and tear film}

Blepharitis and meibomian gland dysfunction are common finding ${ }^{(3,15)}$. Slit-lamp examination of the eyelid margins reveals telangiectases (Figure 2), dilated meibomian glands, excessive seborrheic secretion and collarettes around the eyelashes ${ }^{(15)}$. Excessive meibomian secretion may lead to a soapy aspect of the inferior tear meniscus. Debris in the tear film may also be present. Recurrent hordeolum/chalazion and tear film insufficiency are commonly observed as a consequence of meibomian gland dysfunction ${ }^{(9,15)}$. Dry eyes, with abnormal Schirmer test, were reported in 56-62.5\% of patients with ocular rosacea ${ }^{(24,51,63)}$. Diminished tear break-up time (TBUT) has also been reported in a large majority of patients with ocular rosacea ${ }^{(24,51,60)}$.

Facial edema is an uncommon manifestation ${ }^{(64)}$. Periorbital edema has been reported in the literature and in one particular case, eyelid edema was severe enough to cause visual impairment ${ }^{(65,66)}$

\section{Conjunctiva}

Chronic conjunctivitis characterized by interpalpebral bulbar conjunctival hyperemia may be present ${ }^{(13,15)}$, as well as a chronic papillary reaction ${ }^{(3)}$. Cicatricial conjunctivitis involving the lower lid was described by Akpek et al. as one of the most common ocular surface findings in rosacea ${ }^{(67)}$. Chronic cicatrizing conjunctivitis affecting mainly the upper eyelids, mimicking the classic findings in trachoma,

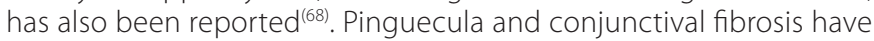
been reported in up to $20 \%$ of patients with ocular rosacea ${ }^{(69,70)}$. Starr and McDonald described a characteristic "arcade" of dilated vessels in the superficial limbal plexus, usually present in the inferior quadrants and not extending into the cornea ${ }^{(1)}$.

Symblepharon formation following surgical excision of a pyogenic granuloma in a patient with ocular rosacea has been reported ${ }^{(71)}$.

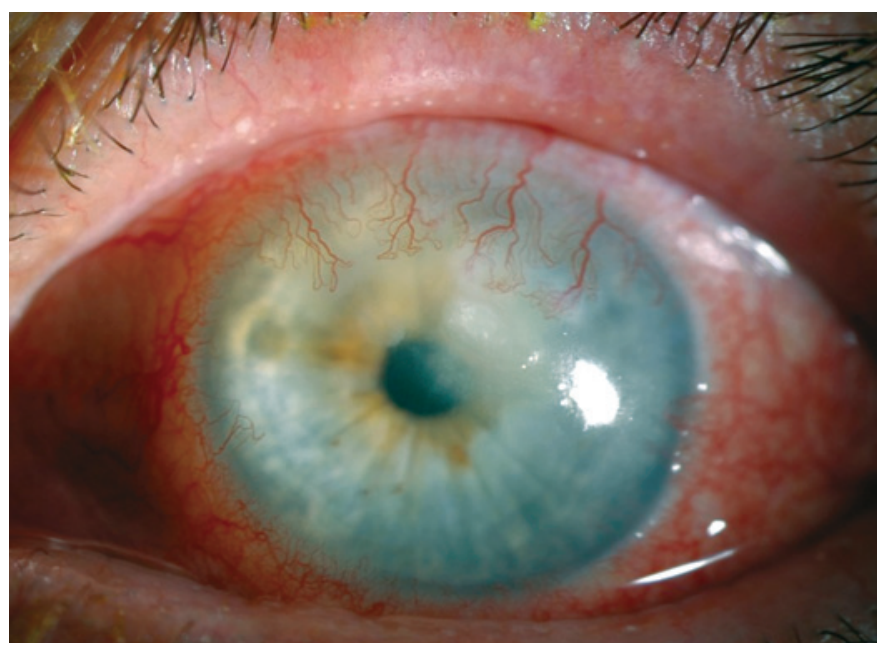

Figure 3. Corneal involvement in a patient with ocular rosacea: peripheral neovascularization associated with subepithelial marginal infiltrates along the advancing vascularborder.

\section{Cornea}

Corneal manifestations may occur in up to $33 \%$ of patients with rosacea ${ }^{(1,3)}$. The inferior cornea is usually affected ${ }^{(15)}$. Corneal involvement typically starts with superficial punctate keratitis on the lower third of the cornea. Peripheral neovascularization associated with subepithelial marginal triangular infiltrates along the advancing vascular border can also occur (Figure 3$)^{(1)}$. If left untreated, these infiltrates may progress centrally and lead to stromal ulceration and even perforation ${ }^{(15,72,73)}$

Recurrent corneal epithelial erosions have been reported in patients with ocular rosacea ${ }^{(67,74,75)}$. Other uncommon corneal findings include pseudodendritic ulcer and pseudokeratoconus, presenting with inferior corneal thinning and high astigmatism ${ }^{(76-78)}$. Secondary infectious keratitis has been reported ${ }^{(79,80)}$

Decreased visual acuity may result from epithelial ulceration, surface irregularities and corneal scarring.

\section{Other ocular findings}

Other ocular findings include iritis, episcleritis and scleritis ${ }^{(5,15)}$. We have previously published a case of spontaneous scleral perforation in a patient with rosacea (Figure 4$)^{(81)}$.

\section{Pediatric rosacea}

The most common ocular signs in pediatric rosacea include meibomian gland dysfunction, telangiectasia, recurrent chalazia, conjunctival hyperemia, superficial punctate epitheliopathy involving the inferior cornea, as well as corneal infiltrates, pannus and neovascularization ${ }^{(16,58)}$. Phlyctenular keratoconjunctivitis has also been associated with ocular rosacea in children ${ }^{(17)}$. Corneal scarring and opacification are possible complications of more advanced disease ${ }^{(17)}$. Donaldson et al., found that $90 \%$ of the children in their series had some degree of corneal involvement at the time of presentation ${ }^{(17)}$.

\section{DIFFERENTIAL DIAGNOSIS OF OCULAR ROSACEA}

The differential diagnosis of ocular rosacea may include staphylococcal and seborrheic blepharokeratoconjunctivitis, and sebaceous gland carcinoma. Given that there is currently no diagnostic test for rosacea, distinguishing ocular rosacea from staphylococcal and seborrheic blepharoconjunctivitis in patients in which ocular signs precede skin findings may be difficult. Sebaceous gland carcinoma

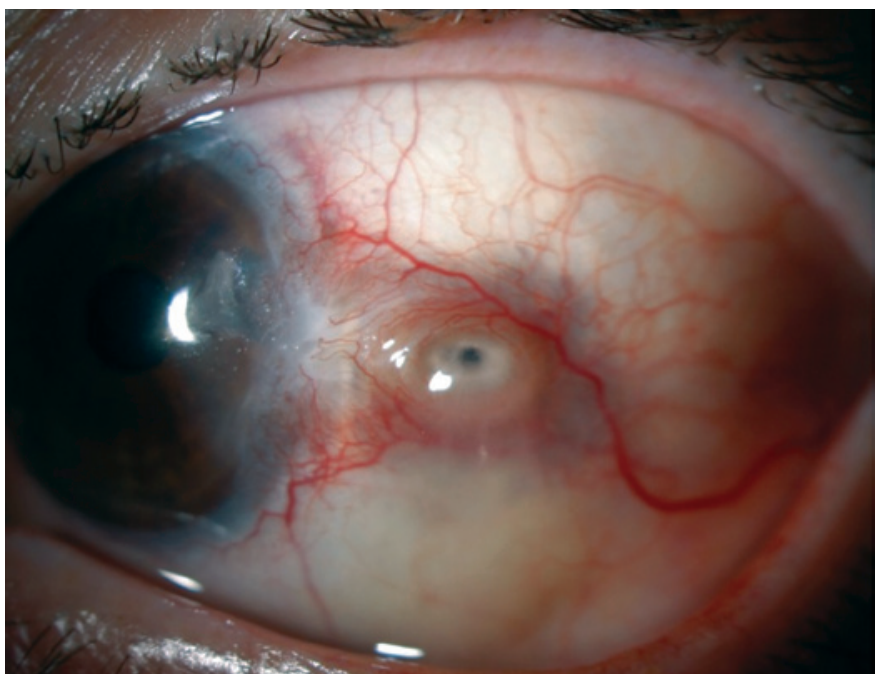

Figure 4. Scleral perforation in a patient with ocular rosacea. 
is often misdiagnosed as chalazion and early recognition is often challenging. For this reason, recurrent chalazia should be excised and sent to histopathology.

\section{TREATMENT}

Rosacea treatment should be initiated as early as possible in order to slow progression of inflammation and decrease development of irreversible fibrosis and ocular morbidity. The severity of the clinical findings and subtypes will help guide therapy. It is important to note that it is not uncommon for patients to present with an overlap of signs, showing features of more than one subtype of the disease ${ }^{(82)}$ Clinicians should therefore identify the clinical features of the individual patient in order to guide the treatment, rather than try to fit the patient into one specific category. Treatment of eye-related symptoms alone may not be effective unless the underlying rosacea is diagnosed and adequately treated.

\section{General measures}

Initial management includes identification and avoidance of trigger factors ${ }^{(10)}$. These factors are usually specific to each individual. Broad-spectrum sunscreen should be used daily for photoprotection ${ }^{(11)}$. Appropriate use of concealing makeup may help disguise upsetting facial features ${ }^{(83)}$. Patients should be informed about the need and importance of regular eye exams ${ }^{(4)}$.

\section{Medical treatment}

\section{Cutaneous rosacea}

There are several treatment options available for rosacea but it is unclear which are the most effective. Early stages of rosacea may be controlled with topical regimens. Medications such as topical metronidazole $(0.75 \%$ and $1 \%$ formulations) and azelaic acid (15\% gel or $20 \%$ cream) are approved for the treatment of mild to moderate papulopustular rosacea, showing similar results ${ }^{(15,61,82,84-88)}$. Sodium sulfacetamide 10\%/sulfur 5\% preparations have also been used with satisfactory results; however, its association with metronidazole cream showed superior efficacy(89). Other topical treatments used "off-label" include clindamycin, erythromycin, pimecrolimus, tacrolimus and tretinoin ${ }^{(61,86,89)}$

When topical treatment alone is not sufficient, systemic therapy should be initiated. Oral tetracyclines (500 mg b.i.d.) and doxycycline (40-100 mg daily from 8-16 weeks) have been shown to safely improve the signs and symptoms of rosacea ${ }^{(84)}$. In 2006, the FDA approved a daily formulation of $40 \mathrm{mg}$ doxycycline monohydrate (Oracea ${ }^{\circledR}$, Galderma) for the treatment of rosacea, although other approved formulations of doxycycline are available. In unresponsive cases and when tetracyclines are contra-indicated or not tolerated, oral azithromycin (500 mg/day for 2 weeks) has been considered a good option ${ }^{(2,90,91)}$. Oral isotretinoin (0.3 to 1.0 $\mathrm{mg} / \mathrm{kg} /$ day) is recommended in more severe intractable cases. The biggest disadvantage of this drug is the risk of teratogenicity and, therefore, all female patients in childbearing age should use proper contraception ${ }^{(92)}$

Diffuse and persistent erythema in erythematotelangiectatic rosacea has been successfully treated with topical oxymetazoline $0.05 \%$ and xylometazoline $0.05 \%$, alpha-adrenergic receptor agonists with strong vasoconstrictive properties ${ }^{(33,34)}$. It is important to note that these medications are not yet FDA-approved for the treatment of rosacea, but have been published in case reports. Another $\alpha$-agonist currently in study showing promising results for the treatment of facial erythema is brimonidine tartrate, a highly selective $\alpha 2$-adrenoreceptor agonist ${ }^{(82,93)}$. Vascular laser therapy and intense pulsed light can be used for treatment of resistant skin telangiectasias and persistent erythema ${ }^{(15,61,93,94)}$.

\section{Ocular rosacea}

Management of mild ocular rosacea requires local measures such as warm compresses, lid hygiene with neutral baby shampoo and instillation of lubricating drops ${ }^{(2,83)}$. Thicker lubricating agents, such as gels and ointments, may be prescribed for more symptomatic dry eyes to promote longer-lasting relief. Topical cyclosporine $0.05 \%$ helps increase tear production and quality ${ }^{(95)}$. Antibiotic ointments prescribed daily, at bedtime, decreases eyelid flora and helps soften collarettes ${ }^{(61)}$.

Moderate ocular rosacea may require systemic therapy ${ }^{(96)}$. Oral tetracycline and doxycycline have been used to successfully treat ocular rosacea as an adjunct therapy to topical treatment ${ }^{(60,61,83,97)}$. As in the management of skin rosacea, tetracyclines may be initially administered $500 \mathrm{mg}$ b.i.d. for 2-3 weeks, and then tapered according to clinical response. Doxycycline possesses anti-angiogenic and anti-inflammatory properties as well as fewer side effects than first generation tetracyclines. Doxycycline may be prescribed in a regimen of $100 \mathrm{mg}$ once or twice daily for 6 to 12 weeks. Many patients may present flare-ups once the medication is discontinued and may therefore require long-term maintenance therapy. However, long-term use of the drug at this dosage has side effects that may compromise regular treatment, such as gastrointestinal intolerance. As previously mentioned, the FDA approved a $40 \mathrm{mg}$ doxycycline formulation (Oracea ${ }^{\oplus}$, Galderma) for the treatment of rosacea. It contains $30 \mathrm{mg}$ immediate-release and $10 \mathrm{mg}$ delayed-release doxycycline that should be administered once daily ${ }^{(98)}$. Significant improvement of ocular rosacea was obtained with regular use of controlled-release doxycycline $40 \mathrm{mg}$, with no side effects leading to discontinuation of therapy ${ }^{(85,99)}$. Azithromycin improved eye symptoms and was considered a good alternative therapy for ocular rosacea, when other drugs are not tolerated ${ }^{(2)}$. Long-term oral consumption of omega 3 fatty acids has been shown to improve the quality of meibomian gland secretion ${ }^{(15)}$

In cases where persistent ocular surface inflammation, episcleritis, scleritis, iritis and sterile keratitis are present, topical corticosteroids or cyclosporine may prove beneficial|(15,61,85,95,100) . Topical cyclosporine $0.05 \%$, used twice daily, was also beneficial in reducing inflammation in posterior blepharitis ${ }^{(15)}$. Long-term use of steroids should be avoided due to the potential side effects, such as glaucoma and cataracts, in which case the use of topical cyclosporine is preferable ${ }^{(15)}$.

In cases of secondary infectious keratitis, antimicrobial agents should be initiated promptly and topical steroids avoided or used with care, along with specific antimicrobial therapy ${ }^{(15,79)}$.

\section{Pediatric ocular rosacea}

Initial treatment should include local measures such as warm compresses and eyelid hygiene with neutral baby shampoo. This routine may be difficult to maintain in children; however, the importance of these measures should be reinforced to the parents. Topical erythromycin ointment may also be used on the eyelid margins ${ }^{(58)}$. Low-dose corticosteroid drops may be necessary to control ocular surface inflammation and treat keratitis, peripheral corneal vascularization and scarring ${ }^{(17)}$.

As in adults, those patients with resistant disease should be prescribed oral therapy. Systemic treatment of ocular childhood rosacea is very similar to that in adults, although one important difference is that tetracyclines are contra-indicated in children younger than 7 years of age ${ }^{(58)}$. Tetracycline and doxycycline, commonly used for therapy in adults, may result in depressed bone growth and dental staining in this age range ${ }^{(17)}$. In these cases, erythromycin $(20 \mathrm{mg} / \mathrm{kg} /$ day) is preferable ${ }^{(16,17,101)}$. Doxycycline (100 mg once or twice daily) is considered a good therapeutic option for older children, since it is usually better tolerated than tetracycline. Long-term treatment with systemic erythromycin and doxycycline proved beneficial in children with ocular rosacea ${ }^{(16)}$. Azithromycin improved eye symptoms and 
may also be considered in young children, where tetracyclines cannot be prescribed ${ }^{(2)}$.

\section{Surgical treatment}

Punctal occlusion may be beneficial in the management of moderate to severe dry eyes. Persistent chalazia may require surgical management and specimen should be sent to pathology.

Corneal thinning and perforations in ocular rosacea patients have been managed using simple corneal sutures, tissue adhesive, amniotic membrane transplantation, and conjunctival flaps (73,102-104). $^{\text {. }}$ Lamellar or full-thickness keratoplasty are other options when surgical intervention becomes necessary, in cases of corneal perforation or opacification ${ }^{(15)}$. Gracner and Gracner chose to perform a keratoplasty to successfully treat an extensive cornealscleral perforation ${ }^{(72)}$.

\section{CONCLUSION AND FUTURE PERSPECTIVES}

Rosacea is a prevalent disorder that may be disfiguring and cause significant social impairment, as well as various degrees of ocular morbidity, if not diagnosed and managed appropriately. Ocular rosacea is often left undiagnosed and no specific diagnostic test is available to date. For this reason, diagnosis relies on a high level of suspicion and clinical observation of characteristic skin manifestations ${ }^{(54)}$. This becomes very challenging in up to $20 \%$ of the patients, when ocular symptoms and signs precede cutaneous features ${ }^{(3)}$. In these cases, a diagnostic test would be of great importance. Future studies may provide a biomarker and an etiologic explanation for this troublesome disorder.

\section{REFERENCES}

1. Starr PA, McDonald A. Oculocutaneous aspects of rosacea. Proc R Soc Med. 1969; 62(1):9-11

2. Bakar O, Demircay Z, Toker E, Cakir S. Ocular signs, symptoms and tear function tests of papulopustular rosacea patients receiving azithromycin. J Eur Acad Dermatol Venereol. 2009:23(5):544-9.

3. Ghanem VC, Mehra N, Wong S, Mannis MJ. The prevalence of ocular signs in acne rosacea: comparing patients from ophthalmology and dermatology clinics. Cornea. 2003:22(3):230-3.

4. Blount BW, Pelletier AL. Rosacea: a common, yet commonly overlooked, condition. Am Fam Physician. 2002;66(3):435-40. Summary for patients in: Am Fam Physician. 2002;66(3):442.

5. Alvarenga LS, Mannis MJ. Rosacea ocular. Surf Ocul. 2005;3(1):41-58

6. Cohen AF, Tiemstra JD. Diagnosis and treatment of rosacea. J Am Board Fam Pract. 2002;15(3): 214-7.

7. National Rosacea Society. 16 million Americans have rosacea and most of them don't know itInternet]. Barrington, Illinois; NRS; 2012. Available from: http://www.rosacea.org

8. Berg M, Lidén S. An epidemiological study of rosacea. Acta Derm Venereol. 1989; 69(5):419-23

9. Spoendlin J, Voegel JJ, Jick SS, Meier CR. A study on the epidemiology of rosacea in the U.K. Br J Dermatol. 2012;167(3):598-605.

10. Baldwin HE. Diagnosis and treatment of rosacea: state of the art. J Drugs Dermatol. 2012;11(6):725-30.

11. Buechner SA. Rosacea: an update. Dermatology. 2005;210(2):100-8.

12. Wollina U. Rosacea and rhinophyma in the elderly. Clin Dermatol. 2011;29(1):61-8. Review.

13. Wise G. Ocular rosacea. Am J Ophthalmol. 1943;26:591-609.

14. Hong E, Fischer G. Childhood ocular rosacea: Considerations for diagnosis and treatment. Australas J Dermatol. 2009;50(4):272-5.

15. Oltz M, Check J. Rosacea and its ocular manifestations. Optometry. 2011;82(2):92-103.

16. Çetinkaya A, Okova YA. Pediatric ocular acne rosacea: long term treatment with systemic antibiotics. Am J Ophthalmol. 2006;142(5):816-21.

17. Donaldson KE, Karp CL, Dunbar MT. Evaluation and treatment of children with ocular rosacea. Cornea. 2007;26(1):42-6.

18. Browning DJ, Rosenwasser G, Lugo M. Ocular rosacea in blacks. Am J Ophthalmol. 1986;101(4):441-4

19. Afonso AA, Sobrin L, Monroy DC, Selzer M, Lokeshwar B, Pflugfelder SC. Tear fluid gelatinase $B$ activity correlates with IL-1alfa concentration and fluorescein clearance in ocular rosacea. Invest Ophthalmol Vis Sci. 1999:40(11):2506-12.

20. Barton K, Monroy CD, Nava A, Pflugfelder SC. Inflammatory cytokines in tears of patients with ocular rosacea. Ophthalmology. 1997;104(11):1868-74.

21. Sobrin L, Liu Z, Monroy DC, Solomon A, Slezer MG, Lokeshwar BL, et al. Regulation of MMP-9 activity in human tear fuid and corneal epithelial culture supernatant. Invest Ophthalmol Vis Sci. 2000;41(7):1703-9.
22. Määttä M, Kari O, Tervahartiala T, Peltonen S, Kari M, Saari M, et al. Tear fluid levels of MMP-8 are elevated in ocular rosacea - treatment effect of oral doxycycline. Graefe's Arch Clin Exp Ophthalmol. 2006;244(8):957-62.

23. Yamasaki K, Kanada K, Macleod D, Borkowski AW, Morizane, S, Nakatsuji T, et al. TLR2 expression is increased in rosacea and stimulates enhanced serine protease production by keratinocytes. J Invest Dermatol. 2011;131(3):688-97.

24. Pisella PJ, Brignole F, Debbasch C, Lozato A, Creuzot-Garcher C, Bara J, et al. Flow cytometric analysis of conjunctival epithelium in ocular rosacea and keratoconjunctivitis sicca. Ophthalmology. 2000;107(10):1841-9.

25. Yamasaki K, Gallo RL. The molecular pathology of rosacea. J Dermatol Sci. 2009; 55(2):77-81.

26. Del Rosso JQ. Advances in understanding and managing rosacea: Part 1. connecting the dots between pathophysiological mechanisms and common clinical features of rosacea with emphasis on vascular changes and facial erythema. J Clin Aesthet Dermatol. 2012;5(3):16-25.

27. Yamasaki K, Di Nardo A, Bardan A, Mrakami M, Ohtake T, Coda A, et al. Increased serine protease activity and cathelicidin promotes skin inflammation in rosacea. Nat Med. 2007;13(8):975-80. Comment in: Nat Med. 2007;13(8):904-6.

28. Meyer-Hoffert U, Schroder JM. Epidermal proteases in the pathogenesis of rosacea. J Investig Dermatol Symp Proc. 2011:15(1):16-23.

29. Schwab VD, Sulk M, Seeliger S, Nowak P, Aubert SM, Mess C, et al. Neurovascular and neuroimmune aspects in the pathophysiology of rosacea. J Investig Dermatol Symp Proc. 2011;15(1):53-62.

30. Wladis EJ, Iglesias BV, Adam AP, Gosselin EJ. Molecular biologic assessment of cutaneous specimens of ocular rosacea. Ophthal Plast Reconstr Surg. 2012;28(4):246-50.

31. Crawford GH, Pelle M, James WD. Rosacea: I. Etiology, pathogenesis, and subtype classification. J Am Acad Dermatol. 2004;51(3):327-41; quiz 324-4. Comment in: J Am Acad Dermatol. 2005;53(6):1104-5. Comment on: J Am Acad Dermatol. 2002; 46(4):584-7.

32. Steinhoff M,Buddenkotte J, Aubert J, Sulk M, Novak P, Schwab VD, et al. Clinical, cellular, and molecular aspects in the pathophysiology of rosacea. J Investig Dermatol Symp Proc. 2011;15(1):2-11.

33. Shanler SD, Ondo AL. Successful treatment of the erythema and flushing of rosacea using a topically applied selective 1-adrenergic receptor agonist, oxymetazoline. Arch Dermatol. 2007:143(11):1369-71

34. Kim JH, Oh YS, Ji JH, Bak H, Ahn SK. Rosacea (erythematotelangiectatic type) effectively improved by topical xylometazoline. J Dermatol. 2011;38(5):510-3.

35. Gomaa AH, Yaar M, Eyada MM, Bhawan J. Lymphangiogenesis and angiogenesis in non-phymatous rosacea. J Cutan Pathol. 2007;34(10):748-53

36. Smith JR, Lanier VB, Braziel RM, Falknhagen KM, White C, Rosenbaum JT. Expression of vascular endothelial growth factor and its receptors in rosacea. Br J Ophthalmol. 2007;91(2):226-9.

37. Kari O, Aho V, Peltonen S, Saari JM, Kari M, Maatta M, et al. Group IIA phospholipase $\mathrm{A}(2)$ concentration of tears in patients with ocular rosacea. Acta Ophthalmol Scand. 2005;83(4):483-6.

38. Lacey N, Delney S, Kavanagh K, Powell FC. Mite-related bacterial antigens stimulate inflammatory cells in rosacea. Br J Dermatol. 2007;157(3):474-81.

39. Szlachic A, Silwowski Z, Karczewska E, Bielanski W, Pytko-Polonczk J, Konturek SJ. Helicobacter pylori and its eradication in rosacea. J Physiol Pharmacol. 1999:50(5): 777-86.

40. Diaz C, O'Callaghan CJ, Khan A, Allchyshyn A. Rosacea: a cutaneous marker of Helicobacter pylori infection? Results of a pilot study. Acta Derm Venereol. 2003; 83(4):282-6

41. Lazaridou E, Giannopoulou c, Fotiadou C, Vakirlis E, TRIGONI a, loannides D. The potential role of microorganisms in the development of rosacea. J Dtsch Dermatol Ges. 2011;9(1):21-5. German

42. O'Reilly N, Menezes N, Kavanagh K. Positive correlation between serum immunoreactivity to Demodex-associated Bacillus proteins and Erythematotelangiectic Rosacea. Br J Dermatol. 2012. [Epub ahead of print].

43. Whitfeld M, Gunasingam N, Leow LJ, Shirato K, Preda V. Staphylococcus epidermidis: a possible role in the pustules of rosacea. J Am Acad Dermatol. 2011;64(1):49-52.

44. Utaş S. Ozbakir S, Turasan A, Utas C. Helicobacter pylori eradication treatment reduces the severity of rosacea. J Am Acad Dermatol. 1999:40(3):433-5. Comment in: J Am Acad Dermatol. 2000;42(3):535-6; J Am Acad Dermatol. 2000;42(3):537-9; J Am Acad Dermatol. 2000:42(3):536-7

45. Szlachcic A. The link between Helicobacter pylori infection and rosacea. J Eur Acad Dermatol Venereol. 2002;16(4):328-33.

46. Dakovic Z, Vesic S, Vukovic J, Milenkovic S, Jankovic Terzic K, Dukic S, et al. Ocular rosacea and treatment of symptomatic Helicobacter pylori infection: a case series. Acta Dermatovenerol Alp Panonica Adriat. 2007;16(2):83-6.

47. Herr $\mathrm{H}$, Você $\mathrm{CH}$. Relationship between Helicobacter pylori and rosacea: it may be a myth. J Korean Med Sci. 2000;15(5):551-4.

48. Schneider MA, Skinner Jr RB, Rosenberg EW, Noah PW, Smith L, Zwarum A. Serological determination of Helicobacter pylori in rosacea patients and controls Clin Res. 1992:40:831A.

49. Bamford JT, Tiden RL, Blankush JL, Gangeness DE. Effect of treatment of Helicobacter pylori Infection on rosacea. Arch Dermatol. 1995;135(6):659-63.

50. Li J, O'Reilly N, Sheha H, Katz R, Raju VK Kavanagh K, Tseng SC. Correlation between ocular Demodex infestation and serum immunoreactivity to Bacillus proteins in patients with facial rosacea. Ophthalmology. 2010;117(5):870-7. 
51. Lazaridou E, Fotiadou C, Ziakas NG, Giannopoulou C, Apalla Z, loannides D. Clinical and laboratory study of ocular rosacea in northern Greece. J Eur Acad Dermatol Venereol. 2011;25(12):1428-31.

52. An HJ, Ninonuevo M, Aquilan J, Liu H, Lebrilla CB, Alvarenga LS, et al. Glycomics analyses of tear fluid for the diagnostic detection of ocular rosacea. J Proteome Res. 2005;4)(6:1981-7.

53. Vieira AC, Um HJ, Ozcan S, Kim JH, Lebrilla CB, Mannis MJ. Glycomic analysis of tear and saliva in ocular rosacea atients: the search for a biomarker. In: XXXIII International Congress of Ophthalmologry. Berlim, Germany, 16-20 feb 2012.

54. Wilkin J, Dahl M, Detmar M, Drake L, Feinstein A, Odom R, et al. Standard classification of rosacea: Report of the National Rosacea Society Expert Committee on the classification and staging of rosacea. J Am Acad Dermatol. 2002:46(4):584-7.Comment in: J Am Acad Dermatol. 2004;51(3):327-41; quiz 342-4.

55. R O. The nosology of rosacea. Cutis. 2004;74(3 Suppl):5-8, 32-4.

56. Wilkin J, Dahl M, Detmar M, Drake L, Liang MH, Odom R, Powell F; National Rosacea Society Expert Committee. Standard grading system for rosacea: report of the National Rosacea Society Expert Committee on the Classification and Staging of Rosacea. $J$ Am Acad Dermatol 2004;50(6):907-12. Comment in: J Am Acad Dermatol. 2006;52(pt 1):539-40.

57. Miguel Al, Salgado MB, Lisboa MS, Henriques F, Paiva MC, Castela GP. Pediatric ocular rosacea: 2 cases. Eur J Ophthalmol. 2012;22(4):664-6.

58. Chamaillard M, Mortemousque B, Boralevi F, Marques da Costa C, Aitali F, Taieb A, et al. Cutaneous and ocular signs of childhood rosacea. Arch Dermatol. 2008;144(2):167-71.

59. Mavrakanas N, Schutz SJ, Dosso AA. Pediatric ocular rosacea. J Pediatr Ophthalmol Strabismus. 2010:47(2):117-20.

60. Quarterman MJ, Johnson DW, Abele DC, Lesher JL Jr, Casco DS, Davis LS. Ocular rosacea. Signs, symptoms, and tear studies before and after treatment with doxycycline. Arch Dermatol. 1997;133(1):49-54. Comment in: Arch Dermatol. 1997; 133(1):89-90.

61. Odom R, Dahi M, Dover J, Draelos Z, Drake L, Macsal M, Powell F, Thiboutot D, Webster GF, Wilkin J; National Rosacea Society Expert Committee on the Classification and Staging of Rosacea. Standard management options for rosacea, part 2: options according to rosacea subtype. Cutis. 2009:84(2):97-104.

62. Keshtcar-Jafari A, Akhyani M, Ehsani AH, Ghiasi M, Lajevardi V, Baradran O, et al. Correlation of the severity of cutaneous rosacea with ocular rosacea. Indian J Dermatol Venereol Leprol. 2009;75(4):405-6.

63. Gudmundsen KJ O'Donnell BF, Powell FC. Schirmer testing for dry eyes in patients with rosacea. J Am Acad Dermatol. 1992;26(2 Pt 1):211-4

64. Chen DM, Crosby DL. Periorbital edema as an initial presentation of rosacea. J Am Acad Dermatol. 1997:37(2 Pt 2):346-8.

65. O'Donnell BF, Foulds IS. Visual impairment secondary to rosacea $\mathrm{Br} J$ Dermatol. 1992;127(3):300-1.

66. Morales-Burgos A, Alvarez Del manzano G, Sánchez JL, Cruz CL. Persistent eyelid swelling in a patient with rosacea. P R Health Sci J. 2009;28(1):80-2

67. Akpek EK, Merchant A, Pinar V, Foster CS. Ocular rosacea: patient characteristics and follow-up. Ophthalmology. 1997;104(11):1863-7.

68. Ravage ZB, Beck AP, Macsai MS, Ching SS. Ocular rosacea can mimic trachoma: a case of cicatrizing conjunctivitis. Cornea. 2004:23(6):630-1.

69. Lima KB, Sousa LB, Santos NC, Barros J de N, Antonio D. [Cost-benefit analysis of ocular examination of patients with rosacea]. Arq Bras Oftalmol. 2005;68(1):37-43. Portuguese.

70. Faraj HG, Hoan.g-Xuan T Chronic cicatrizing conjunctivitis. Curr Opin Ophthalmol. 2001;12(4):250-7.

71. Rahman MQ, Lim Y, Roberts F, Ramaesh K. Fibrosing blepharo-conjunctivitis following pyogenic granuloma in ocular acne rosacea. Ocul Immunol Inflamm. 2012;18(5):346-8.

72. Gracner B, Pahor D, Gracner T. [Repair of an extensive corneoscleral perforation in a case of ocular rosacea with a keratoplasty]. Klin Monbl Augenheilkd. 2006; 223(10):841-3. German.

73. Al Arfaj K, Al Zamil W. Spontaneous corneal perforation in ocular rosacea. Middle East Afr J Ophthalmol. 2010;17(2):186-8.

74. Jenkins MS, Brown SI, Lempert SL, Weinberg RJ. Ocular rosacea. Am J Ophthalmol. 1979:88(3 Pt 2):618-22.

75. Ramamurthi S, Rahman MQ, Dutton GN, Ramaesh K. Pathogenesis, clinical features and management of recurrent corneal erosions. Eye (Lond). 2006;20(6):635-44. Comment in: Eye (Lond). 2007;21(3):439-40. Eye (Lond). 2007;21(8):1128.

76. Lee WB, Darlington JK, Mannis MJ, Schwab IR. Dendritic keratopathy in ocular rosacea. Cornea. 2005:24(5):632-3.
77. Dursun D, Piniella AM, Pflugfelder SC. Pseudokeratoconus caused by rosacea. Cornea. 2001;20(6):668-9.

78. Jain V, Shome D, Natarajan S. Pseudodendritic keratitis in ocular rosacea causing a diagnostic dilemma. Indian J Ophthalmol. 2007:55(6):480-1.

79. Jain V, Shome D, Sajnani M, Natarajan S. Fungal keratitis associated with ocular rosacea. Int Ophthalmol. 2010;30(3):239-44.

80. Robertson DM, Cavanagh HD. Pseudomonas aeruginosa keratitis in an atopic silicone hydrogel lens wearer with rosacea. Eye Contact Lens. 2005;31(6):254-6.

81. Vieira AC, Mannis MJ. Spontaneous scleral perforation in ocular rosacea. Vision Pan-Amer. 2009;8(1):149-51.

82. Del Rosso JQ. Advances in understanding and managing rosacea: Part 2. The central role, evaluation, and medical management of diffuse and persistent facial erythema of rosacea. J Clin Aesthet Dermatol. 2012;5(3):26-36.

83. Gupta AK, Chaudhry MM. Rosacea and its management: an overview. J Eur Acad Dermatol Venereol. 2005:19(3):273-85.

84. van Zuuren EJ, Kramer SF, Carter BR, Graber MA, Fedorowicz Z. Effective and evidence-based management strategies for rosacea: summary of a Cochrane systematic review. Br J Dermatol. 2011;165(4):760-81. Comment in: Br J Dermatol. 2011; 165(4):707-8

85. van Zuuren EJ, Karmer S, Carter B, Graber MA, Fedorowicz Z. Interventions for Rosacea. Cochrane Database Syst Rev. 2011;16(3):CD003262.

86. Gooderham M. Rosacea and its topical management. Skin Therapy Lett. 2009;14(2):1-3.

87. Wolf JE Jr, Kerrouche N, Arsonnaud S. Efficacy and safety of once-daily metronidazole $1 \%$ gel compared with twice-daily azelaic acid 15\% gel in the treatment of rosacea. Cutis. 2006;77(4 Suppl):3-11.

88. Barnhorst DA Jr, Foster JA, Chern KC, Meisler DM. The efficacy of topical metronidazole in the treatment of ocular rosacea. Ophthalmology.. 1996;103(11):1880-3.

89. Pelle MT, Crawford GH, James WD. Rosacea: II. Therapy. J Am Acad Dermatol. 2004;51(4):499-512; quiz 513-4

90. Kim JH, Oh Y, Choi EH. Oral azithromycin for treatment of intractable rosacea. J Korean Med Sci. 2011;26(5):694-6

91. Modi S, Harling M, Rosen T. Azithromycin as an alternative rosacea therapy when tetracyclines prove problematic. J Drugs Dermatol. 2008;7(9):898-9.

92. Park H, Dell Rosso JQ. Use of oral isotretinoin in the management of rosacea. J Clin Aesthet Dermatol. 2011:4(9):54-61.

93. Fowler J, Jarrat M, Moore A, Meadows K, Pollack A, Steinholf M, Liu Y, Leoni M; Brimonidine Phase II study Group. Once-daily topical brimonidine tartrate gel $0.5 \%$ is a novel treatment of moderate to severe facial erythema of rosacea: results of two multicenter, randomized and vehicle-controlled studies. Br J Dermatol. 2012;166(3):633-41.

94. Odom R, Dahl M, Dover J, Draelos Z, Drake L, Macsai M, Powell F, Thiboutot D, Webster GF, Wilkin J; National Rosacea society Expert Committee on the Classification and Staging of Roasacea. Standard management options for rosacea, Part 1: overview and broad spectrum of care. Cutis. 2009;84(1):43-7.

95. Schechter BA, Katz RS, Friedman LS. Efficacy of topical cyclosporine for the treatment of ocular rosacea. Adv Ther. 2009;26(6):651-9.

96. Goldgar C, Keahey DJ, Houchins J. Treatment options for acne rosacea. Am Fam Phys. 2009;80(5):461-8

97. Stone DU, Chodosh J. Oral tetracyclines for ocular rosacea: an evidence-based review of the literature. Cornea. 2004;23(1):106-9.

98. Valentin S, Morales A, Sánchez JL, Rivera A. Safety and efficacy of doxycycline in the treatment of rosacea. Clin Cosmet Investig Dermatol. 2009;2:129-40.

99. Pfeffer I, Borelli C, Zierhut M, Schaller M. Treatment of ocular rosacea with $40 \mathrm{mg}$ doxycycline in a slow release form. J Dtsch Dermatol Ges. 2011;9(11):904-7.

100. Donnenfeld E, Plufgfelder SC. Topical ophthalmic cyclosporine: pharmacology and clinical uses. Surv Ophthalmol. 2009;54(3):321-38. Comment in: Surv Ophthalmol. 2010;55(2):189; author reply 189,

101. Hong E, Fischer G. Childhood ocular rosacea: considerations for diagnosis and treatment. Australas J Dermatol. 2009;50(4):272-5.

102. Jain AK, Sukhija J. Amniotic membrane transplantation in ocular rosacea. Ann Ophthalmol (Skokie). 2007;39(1):71-3

103. Sandinha T, Zaher SS, Roberts F, Devlin HC, Dhillon B, Ramaesh K. Superior forniceal conjunctival advancement pedicles (SFCAP) in the management of acute and impending corneal perforations. Eye (Lond). 2006;20(1):84-9. Comment in: Eye (Lond). 2007:21(2):283-4; Eye (Lond). 2006; 20(12):1468.

104. Bodaghi B, Levy C, Votan P, Hoang-Xuan T. [Value of cyanoacrylate tissue adhesives in peripheral corneal ulcers of inflammatory origin]. J Fr Ophtalmol. 1996;19(2):127-32. French. 